\title{
Stage IB Fallopian Tube Cancer AJCC v6 and $v 7$
}

National Cancer Institute

\section{Source}

National Cancer Institute. Stage IB Fallopian Tube Cancer A/CC v6 and v7. NCI Thesaurus.

Code 66270.

Stage IB includes: T1 b, N0, M0. T1 b: Tumor limited to both tubes, without penetrating the serosal surface; no ascites. N0: No regional lymph node metastasis. M0: No distant metastasis. (AJCC 6th and 7th eds.) 